\title{
KNOWLEDGE AND ATTITUDE OF IRAQI PHARMACISTS IN BAGHDAD COMMUNITY TOWARD ADVERSE DRUG REACTIONS MONITORING
}

\author{
SAMER IMAD MOHAMMED ${ }^{1 *}$, AMNA FOUAD ABDUL AL-RAZAQ ${ }^{2}$
}

${ }^{1}$ Department of Clinical Pharmacy, College of Pharmacy, Baghdad University, Baghdad, Iraq. ${ }^{2}$ Directorate of Ninava Health, Ministry of Health, Ninava, Iraq. Email: drsamerimad@gmail.com

Received: 14 December 2016, Revised and Accepted: 04 January 2016

\section{ABSTRACT}

Objective: Adverse drug reactions (ADRs) can lead to many complications associated with the use of medications. In Iraq, where a wide range of medications misused widely due to different reasons, the Iraqi Pharmacovigilance (PV) program started out few years ago to collect information about adverse drugs reactions and since the success of this program depends on the effective participation of all medical staffs including pharmacists in this program. This study aimed to assess the knowledge, attitude, and degree of awareness of Iraqi pharmacists in Baghdad community toward adverse drugs reactions monitoring and PV program.

Methods: This study was a cross-sectional descriptive survey based on individual questionnaire that administered in English to a convenience sample of 150 pharmacists working in 3 colleges of pharmacy, 20 community pharmacies, and 3 hospitals situated in different areas of Baghdad which is the capital of Iraq. The questionnaire consists of three parts that collect demographic data on the participants and their knowledge, attitudes toward PV.

Results: Although about $62 \%$ of pharmacists have observed ADRs in their practice, only half of the respondents have heard about the term PV, $48 \%$ were aware of the national PV program. Moreover, $47.33 \%$ of the respondents mentioned that ADRs associated with herbal products should not be reported. Although $79 \%$ of the respondents thought that reporting ADRs are a pharmacist's duty nevertheless $82 \%$ of them thought that ADRs reporting in Iraq are not widely promoted by the relevant authority. The study showed high tendency for participation in and ADR monitoring program. Interestingly, $60 \%$ of respondents report that their workplace does not encourage them for reporting ADRs while $48 \%$ of respondents indicated that they do not have enough time for reporting ADRs and 38\% of them declared their fearing of facing legal problem from that.

Conclusion: Iraqi pharmacists although have a high tendency in participation in ADRs monitoring program but have a poor knowledge about PV practices; they lack understanding of the details about the national PV system and ADRs reporting process and may need more information on how ADRs reporting are performed.

Keywords: Knowledge, Attitudes, Adverse drug reactions, Pharmacovigilance.

(c) 2017 The Authors. Published by Innovare Academic Sciences Pvt Ltd. This is an open access article under the CC BY license (http://creativecommons. org/licenses/by/4. 0/) DOI: http://dx.doi.org/10.22159/ajpcr.2017.v10i4.16595

\section{INTRODUCTION}

Medicines have substantial benefits to human health; however, most times, adverse reactions or unwanted effects produced with their beneficial effect [1].

This adverse drug reaction (ADR) or unwanted effect simply can be defined as an injury caused by taking a medication [2]. This usually can lead to many complications associated with the use of medicines such as the increase in the duration of hospital stay [3] and hospital costs [4]. Moreover, ADRs can lead to death in about $2.9 \%$ of hospital admissions [5]. Although ADRs are preventable, still regarded as one the top 10 leading causes of mortality in many countries [6].

After the "thalidomide tragedy," many countries have established drug monitoring systems (Pharmacovigilance [PV] system) for early detection and prevention of possible drug-related morbidity and mortality and to minimize the financial costs associated with preventable adverse events [7]. During the last decade, PV activities have evolved widely and the postmarketing surveillance (PV system) help many drug companies to frame the full benefit-risk profile of their drugs in the real world setting which is more effective than clinical trials that only help a company in initial reporting of safety profile [8].

The WHO establish education center in the Netherlands, to develop PV curricula for medical school to overcome the inefficiency of training and education of medical staffs regarding ADRs monitoring [9]. There are differences among countries in the occurrence of ADRs and other drugrelated problems [10]. In Iraq, which is one of the third world countries, the dispensing of many medications is illegal, and many people stored medications in their houses in inappropriate storage conditions; furthermore, they use it most times incorrectly without any physician advice [11]. In one study that evaluate the use of analgesics by Iraqi people, the result showed a misuse of using these medications and most consumers have no information about the side effect, even more higher percentage of them do not adhere to doses prescribed [12].

The former two studies showed that the Iraqi people have a high affinity to confront ADRs as a result of their misuse of medications; so to decrease the impact of this dilemma, the Iraqi PV center has been established in the Directorate of technical affairs, Ministry of Health $(\mathrm{MOH})$ to be responsible for the collection, and evaluation of information on pharmaceutical products marketed in Iraq, with particular reference to adverse reactions [13].

As the success of any PV system depends on the cooperation of all medical professions including pharmacists in reporting suspecting ADRs, especially to new drugs [14].

Many studies conclude that improving hospital and community pharmacist knowledge and experiences toward ADRs reporting can play a significant role in the prevention of ADRs in addition to improving other healthcare professionals' knowledge about ADRs reporting [15]. 
This study is the foremost study in Iraq designed to evaluate the knowledge of Iraqi pharmacists in Baghdad community toward ADRs monitoring program (PV system) and assess their attitude to participate in this program.

\section{METHODS}

This study was a cross-sectional descriptive survey based on individual questionnaire developed by authors of this study based on multiple pretested questionnaires in similar literatures. The questionnaire approved by Scientific Committee in Department of Clinical Pharmacy, college of Pharmacy, Baghdad University (Tables 1-3).

The questionnaire administered in English to a convenience sample of 150 pharmacists working in 3 colleges of pharmacy, 20 community pharmacies, and 3 hospitals situated in different areas of Baghdad which is the capital of Iraq. The study sample was collected during

\section{Table 1: Demographic characteristics of the respondents}

\begin{tabular}{lll}
\hline Characteristics & Category & Total N (\%) \\
\hline Gender & Male & $65(43.3)$ \\
& Female & $85(56.7)$ \\
Age & $23-33$ & $63(42)$ \\
& $34-44$ & $48(32)$ \\
Qualification & $>44$ & $39(26)$ \\
& Diploma & $9(6)$ \\
& Bachelor & $95(63.3)$ \\
Work experience & Master & $29(19.3)$ \\
& PhD & $17(11.3)$ \\
Workplace & $1-5$ years & $51(34)$ \\
& 6-10 years & $34(22.6)$ \\
& $>10$ years & $65(43.3)$ \\
& Pharmacy & $50(33.33)$ \\
& Hospital & $43(28.67)$ \\
& College & $41(27.33)$ \\
& Else & $16(10.67)$ \\
\hline
\end{tabular}

Sample size $\mathrm{N}=150$ the periods from November 2015 to September 2016. The study was approved by the Ethics and Research Committee in the Department of Clinical Pharmacy, College of Pharmacy, Baghdad University. Verbal consent was obtained from all participants who agreed to participate in the study after explaining the objectives, importance, and benefits of this study. Participants were told that all information provided was completely confidential with a nameless presentation of the results. The questionnaire consists of three parts that collect demographic data on the participants and their knowledge, attitudes toward PV.

\section{Statistical analysis}

The collected data from the completed questionnaires were assessed for descriptive statistics such as frequencies and percentages. Statistical analysis was analyzed using Microsoft Excel program 2013.

\section{RESULTS}

\section{Participants' demographic data}

The questionnaire administered to 200 pharmacists, but only 150 accept to fill it. The response rate of the survey was $75 \%$. The age of pharmacists participated ranging from 23 to 65 years. The highest percentage was females $(56.7 \%)$, qualified as bachelor pharmacists (63.3\%) and with work experience more than 10 years (43.3\%). Details of the respondents' demographic profile are illustrated in Table 1.

Knowledge of ADR reporting and monitoring by respondents Half of the respondents have heard about PV, $43.33 \%$ were aware of the national PV program. On the other hand, $34.67 \%$ of the respondents mentioned that ADRs associated with herbal products should not be reported, whereas $74 \%$ thought that the responsible organization for monitoring ADRs is $\mathrm{MOH}$ as shown in Table 2.

\section{Attitudes toward ADR reporting}

Table 3 shows that $79 \%$ of the respondents thought that reporting ADRs is a pharmacist's duty and $82 \%$ who thought that ADRs reporting in Iraq is not widely promoted by relevant authority whereas $74 \%$ declared their interest in the participation in ADR reporting system, 62\% have

Table 2: Knowledge of ADRs reporting and monitoring by respondents

\begin{tabular}{|c|c|c|c|}
\hline \multirow[t]{2}{*}{ Identified knowledge } & \multicolumn{3}{|c|}{ Responses, N (\%) } \\
\hline & Yes & No & Not sure \\
\hline Did you hear about the term PV? & $76(50.67)$ & $61(40.67)$ & $13(8.66)$ \\
\hline Are you aware about the national PV program? & $65(43.33)$ & $66(44)$ & 19 (12.67) \\
\hline \multirow{2}{*}{$\begin{array}{l}\text { Do you think that ADRs associated with herbal } \\
\text { products should not be reported in PV? }\end{array}$} & $52(34.67)$ & $71(47.33)$ & $27(18)$ \\
\hline & $\begin{array}{l}\text { Pharmacists } \\
\text { syndicate }\end{array}$ & МOH & Don't know \\
\hline $\begin{array}{l}\text { Who do you think the responsible organization } \\
\text { for collecting and monitoring ADRs in Iraq? }\end{array}$ & $24(16)$ & $111(74)$ & $15(10)$ \\
\hline
\end{tabular}

Sample size N=150. PV: Pharmacovigilance, ADR: Adverse drug reactions, MOH: Ministry of Health

Table 3: Responses of respondents to the attitude related questions

\begin{tabular}{|c|c|c|c|}
\hline \multirow[t]{2}{*}{ Identified attitudes } & \multicolumn{3}{|c|}{ Responses, N (\%) } \\
\hline & Yes & No & Not sure \\
\hline Do you think that reporting ADR is a pharmacist duty? & $119(79.33)$ & $15(10)$ & $16(11.67)$ \\
\hline $\begin{array}{l}\text { Do you think that ADR reporting in Iraq is not widely } \\
\text { promoted by relevant authorities? }\end{array}$ & $124(82.67)$ & $14(9.33)$ & $12(8)$ \\
\hline $\begin{array}{l}\text { Are you interested in participating in the ADR reporting } \\
\text { system? }\end{array}$ & $111(74)$ & $26(17.33)$ & $13(8.67)$ \\
\hline Have you observed ADRs cases in your practice? & $94(62.67)$ & $39(26)$ & $17(11.33)$ \\
\hline Does your work place encourage you to report an ADR? & $38(25.33)$ & $91(60.67)$ & $21(14)$ \\
\hline Do you think that pharmacists do not have enough time? & $72(48)$ & $67(44.67)$ & $11(7.33)$ \\
\hline Are you afraid of facing legal problems from that? & $57(38)$ & $65(43.33)$ & $28(18.67)$ \\
\hline
\end{tabular}

Sample size N=150. ADR: Adverse drug reactions 
observed ADRs in their practice; however, $60 \%$ of respondents report that their workplace does not encourage them for reporting ADRs, 48\% of respondents showed that they do not have enough time for reporting ADRs, and $38 \%$ of them declared their fearing of facing legal problem from that.

\section{DISCUSSION}

This cross-sectional survey was conducted with a convenience sample of 150 pharmacists to collect information on what they know, believe, and do regarding adverse drugs reaction monitoring and the Iraqi PV program. The present study is similar to previous studies conducted in Yemen [16], many developing countries [17,18], and developed countries $[19,20]$.

The study has shown a gap in the knowledge of Iraqi pharmacists about ADRs monitoring center in Iraq and PV system and about 44\% of participants do not have a full knowledge about this center and $47 \%$ of them did not think that they are responsible for reporting adverse reactions related to herbal products. Although these percentages regarded low in comparison to another studies performed other countries like in Saudi Arabia where $78.8 \%$ did not know that pharmacists can submit ADRs reports online [21] or in a pilot study conducted in Turkey, where only $17.2 \%$ of the pharmacists had any knowledge about "PV" [18] in addition to a similar study conducted in Yemen, where $69 \%$ of pharmacists unaware of national PV program [16].

Inadequate knowledge of healthcare professionals is most probably due to the fact that drug safety is not taken seriously worldwide, particularly in developing countries $[17,18]$ although it should be one of the top priorities in healthcare programs.

Furthermore, the PV center activities are still inadequate with no sufficient advertising about it in Iraq. Despite the findings of relatively high rates of unawareness and inadequate knowledge among participants, $79 \%$ of them thought that reporting ADRs is a pharmacist's duty and that similar to many previous studies have shown that while the right attitude for ADR reporting exists among most of the pharmacists and physicians, the actual practice of ADRs reporting is lacking [17]. The main problem faced national PV systems worldwide is underreporting [2].

Although high percentage $(79 \%)$ of participant said that reporting adverse drug reaction is a pharmacist duty and more than $62.67 \%$ observe ADR during their normal work, all of them did not report these ADR and that similar to many studies in India [17], Mumbai [22], and Ahmedabad [23] have shown that prescribers have high knowledge and attitude with regard to ADRs reporting but practice it poorly. This can be attributed to many reasons such as unawareness of the existence of a national ADRs reporting system, the workplace did not encourage them to report an ADR as 60.67 , also about $38 \%$ of participants afraid of facing legal problems from that or they do not have enough time to report these ADRs (48\%).

The effectiveness of PV activities in a country is directly dependent on the active participation of healthcare professionals, patients, and consumers [24]. Fortunately, all respondents in this study were in favor of the idea of setting up the ADRs reporting system in Iraq and about three quarters of them were willing to be involved in the implementation of the system in Iraq. To improve Iraqi patient's safety and quality of life, pharmacists and other medical staffs need educational programs and training to improve their knowledge about ADRs monitoring process to encourage them to be involved in this task. These were similar to the results of a study conducted in Nigeria [25], which showed the role of continuous medical education; training programs for medical staffs to report ADRs and helped in improving patient's safety and medical care. Furthermore, the center must take his role to raise the awareness of Iraqi patients to improve patient self- reporting manner to increase the reporting of ADRs. The benefits of this idea have been confirmed in different studies [26,27].

\section{REFERENCES}

1. Griffin JP. The evolution of human medicines control from a national to an international perspective. Adverse Drug React Toxicol Rev 1998;17(1):19-50.

2. Edwards IR, Aronson JK. Adverse drug reactions: Definitions, diagnosis, and management. Lancet 2000;356(9237):1255-9.

3. Classen DC, Pestotnik SL, Evans RS, Lloyd JF, Burke JP. Adverse drug events in hospitalized patients. Excess length of stay, extra costs, and attributable mortality. JAMA 1997;277:301-6.

4. Suh DC, Woodall BS, Shin SK, Hermes-De Santis ER. Clinical and economic impact of adverse drug reactions in hospitalized patients. Ann Pharmacother 2000;34:1373-9.

5. Mouton JP, Mehta U, Parrish AG, Wilson DP, Stewart A, Njuguna CW, et al. Mortality from adverse drug reactions in adult medical inpatients at four hospitals in South Africa: A cross-sectional survey. Br J Clin Pharmacol 2015;80(4):818-26.

6. World Health Organization. WHO Policy Perspectives on Medicines. Looking at the Pharmacovigilance: Ensuring the Safe Use of Medicines. Geneva: WHO; 2004. Available from: http://www.whqlibdoc.who.int/ hq/2004/WHO EDM 2004.8.pdf.

7. Feldschreiber $\mathrm{P}$, Breckenridge A. After thalidomide - Do we have the right balance between public health and intellectual property. Rev Recent Clin Trials 2015;10(1):15-8.

8. Jacob D, Marrón B, Ehrlich J, Rutherford PA. Pharmacovigilance as a tool for safety and monitoring: A review of general issues and the specific challenges with end-stage renal failure patients. Drug Healthc Patient Saf 2013;5:105-12.

9. Venulet J. The drug monitoring programme. In: Drug Surveillance. Geneva: World Health Organization; 1994. p. 13-21.

10. World Health Organization. Safety of medicines: A guide to detecting and reporting adverse drug reactions: Why health professionals need to take action. In: Safety of Medicines: A Guide to Detecting and Reporting Adverse Drug Reactions: Why Health Professionals Need to Take Action. Geneva: WHO; 2002.

11. Jassim AM. In-home drug storage and self-medication with antimicrobial drugs in Basrah, Iraq. Oman Med J 2010;25(2):79-87.

12. Mohammed SI. Evaluation of analgesics use and misuse by Iraqi patients in Baghdad community. Asian J Pharm Clin Res 2016;9(1):303-7.

13. Alwan MH. Guidelines for Detecting \& Reporting Adverse Drug Reactions in Iraq Individual Case Safety

Reports, Iraqi Pharmacovigilance Center Version 1. Ministry of health, Iraq 2012.; 2012. Retrieved from http://www.webcache.googleusercontent.com/ search?q=cache:vZmQG_hKkoJ:www.who-umc.org/graphics/28554. $\mathrm{pdf}+\& \mathrm{~cd}=1 \& \mathrm{hl}=\mathrm{en} \& \mathrm{ct}=\overline{\mathrm{cln}} \mathrm{k} \& \mathrm{gl}=\mathrm{iq}$. [Last accessed on

14. Khalili H, Mohebbi N, Hendoiee N, Keshtkar AA, Dashti-Khavidaki S. Improvement of knowledge, attitude and perception of healthcare workers about ADR, a pre- and post-clinical pharmacists' interventional study. BMJ Open 2012;2(1):e000367

15. van Grootheest AC, de Jong-van den Berg LT. The role of hospital and community pharmacists in pharmacovigilance. Res Social Adm Pharm 2905:1(1):126-33 3́dorabbo A, Basaleem H, Jha N, Alshammari T, Shankar PR. Knowledge, attitude beliefs and practices of community pharmacy dispensers in Aden, Yemen towards adverse drug reaction reporting. World J Pharm Sci 2015;3(10):2111-8.

17. Ahmad A, Patel I, Balkrishnan R, Mohanta GP, Manna PK. An evaluation of knowledge, attitude and practice of Indian pharmacists towards adverse drug reaction reporting: A pilot study. Perspect Clin Res 2013;4(4):204-10.

18. Toklu HZ, Uysal MK. The knowledge and attitude of the Turkish community pharmacists toward pharmacovigilance in the Kadikoy district of Istanbul. Pharm World Sci 2008;30(5):556-62.

19. Green CF, Mottram DR, Rowe PH, Pirmohamed M. Attitudes and knowledge of hospital pharmacists to adverse drug reaction reporting. Br J Clin Pharmacol 2001;51(1):81-6.

20. van Grootheest AC, Mes K, de Jong-van den Berg LT. Attitudes of communitypharmacists in the Netherlands towards adverse drug reaction reporting. Int J Pharm Pract 2002;10:267-72.

21. Mahmoud MA, Alswaida Y, Alshammari T, Khan TM, Alrasheedy A, Hassali MA, et al. Community pharmacists' knowledge, behaviors and experiences about adverse drug reaction reporting in Saudi Arabia. Saudi Pharm J 2014;22(5):411-8.

22. Gupta P, Udupa A. Adverse drug reaction reporting and pharmacovigilance: Knowledge, attitudes and perceptions amongst resident doctors. J Pharm Sci Res 2011;3(2):1064-9. 
23. Desai CK, Iyer G, Panchal J, Shah S, Dikshit RK. An evaluation of knowledge, attitude, and practice of adverse drug reaction reporting among prescribers at a tertiary care hospital. Perspect Clin Res 2011;2(4):129-36

24. Olsson S, Pal SN, Dodoo A. Pharmacovigilance in resource-limited countries. Expert Rev Clin Pharmacol 2015;8(4):449-60.

25. Oshikoya KA, Awobusuyi JO. Perceptions of doctors to adverse drug reaction reporting in a teaching hospital in Lagos, Nigeria. BMC Clin
Pharmacol 2009;9:14

26. Blenkinsopp A, Wilkie P, Wang M, Routledge PA. Patient reporting of suspected adverse drug reactions: A review of published literature and international experience. Br J Clin Pharmacol 2007;63(2):148-56.

27. van Hunsel F, Passier A, van Grootheest K. Comparing patients' and healthcare professionals' ADR reports after media attention: The broadcast of a Dutch television programme about the benefits and risks of statins as an example. Br J Clin Pharmacol 2009;67(5):558-64. 